DOI: https://doi.org/10.47405/mjssh.v5i12.614

\begin{tabular}{|c|c|}
\hline 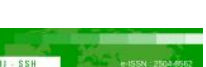 & Malaysian Journal of Social Sciences and Humanities (MJSSH) \\
\hline Malaysian Journal of & Volume 5, Issue 12, December 2020 \\
\hline (Mu-ssH) & e-ISSN : 2504-8562 \\
\hline & $\begin{array}{l}\text { Journal home page: } \\
\text { www.msocialsciences.com }\end{array}$ \\
\hline
\end{tabular}

\title{
Cabaran Usahawan Muda dalam Perniagaan Industri Kecil dan Sederhana (IKS) di Malaysia
}

\author{
Muhamamd Zulhafizi Mohd Yusof ${ }^{1}$, Zurinah Tahir ${ }^{1}$, Jalaluddin Abdul Malek ${ }^{1}$, Ali Salman ${ }^{2}$ \\ ${ }_{1}^{1}$ Pusat Kajian Pembangunan, Sosial dan Persekitaran, Fakulti Sains Sosial dan Kemanusiaan, \\ Universiti Kebangsaan Malaysia (UKM) \\ 2Pusat Pengajian Bahasa dan Pembangunan Insaniah, Universiti Malaysia Kelantan (UMK)
}

Correspondence: Jalaluddin Abdul Malek(jbam@ukm.edu.my)

\begin{abstract}
Abstrak
Sektor perniagaan Industri Kecil dan Sederhana (IKS) dianggap penting memandangkan ia memberikan sumbangan yang besar kepada pendapatan ekonomi negara sekali gus melahirkan usahawan muda berjaya. Usahawan muda yang berjaya bukan sahaja mencipta perniagaan baru malahan meningkatkan peluang pekerjaan dan sebagainya. Kejayaan usahawan muda dalam bidang perniagaan IKS memberikan satu impak positif dalam pembangunan ekonomi negara. Oleh itu, objektif kajian adalah bertujuan untuk mengkaji faktor-faktor yang mendorong kejayaan usahawan muda dalam menghadapi cabaran perniagaan Industri Kecil dan Sederhana (IKS) di Malaysia. Kajian ini menggunakan kaedah kuantitatif yang melibatkan seramai 138 orang responden yang kini bergelar Local Champion yang terdiri daripada usahawan muda yang berjaya dalam perniagaan (IKS) masingmasing. Kesemua responden merupakan Local Champion yang telah terlibat secara langsung di dalam Program Rural Business Challenge dan menetap di sekitar Malaysia yang terdiri daripada Zon Timur, Zon Tengah/Selatan, Zon Utara, Sabah dan juga Sarawak. Data yang diperoleh daripada responden akan dianalisis. Faktor pendorong kejayaan yang dikaji dibahagikan kepada 7 dimensi iaitu Sikap/Minat/Kesedaran diri sendiri, Modal, Pemasaran yang baik, Pemikiran Inovatif dan kreatif, Persekitaran Perniagaan, Kemahiran dan Pengetahuan serta Pengurusan Organisasi dan Kerjasama Luar. Dapatan kajian juga menunjukkan bahawa faktor "Sikap, Minat, Kesedaran diri sendiri" bagi seseorang usahawan itu merupakan faktor paling utama yang mendorong kejayaan seseorang usahawan muda dalam menjalankan perniagaan Industri Kecil dan Sederhana (IKS). Kesimpulannya, sikap usahawan yang berdisiplin tinggi dalam mengendalikan perniagaan, berani dan sanggup menghadapi risiko, berfikiran kreatif dan inovatif, sentiasa mendalami ilmu perniagaan sangat menyumbang terhadap kejayaan usahawan muda IKS di Malaysia bagi mengembangkan lagi perniagaan ke arah peringkat global dan akhirnya menyumbang kepada pembangunan ekonomi negara. Segala faktor dimensi cabaran tersebut sangat mempengaruhi seseorang usahawan untuk mencapai kejayaan sekali gus bagi meningkatkan pembangunan ekonomi negara dan usaha ini harus berterusan dilaksanakan untuk menambahbaikkan kualiti kehidupan komuniti dan masyarakat setempat.
\end{abstract}

Kata kunci: faktor kejayaan, industri kecil dan sederhana, keusahawanan, cabaran usahawan muda, pembangunan ekonomi

\section{Challenges of Young Entrepreneurs in Small and Medium Industries (SMI) in Malaysia}

\author{
Abstract
}


The Small and Medium Industry (SMI) sector is important from the viewpoint of its sizable contribution to the national economy, while facilitating the rise of successful young entrepreneurs. These young entrepreneurs do not only set up new businesses, but they also increase employment opportunities in various industries. The success of young entrepreneurs in SMIs creates a positive impact on the economic development of the country. The objective of this study is to examine the factors that enable the success of young entrepreneurs in facing various challenges in SMI businesses in Malaysia. The study used a quantitative methodology involving 138 respondents who were successful young entrepreneurs in their respective SMI businesses. These Local Champions who had previously been involved in the Rural Business Challenge Program came from various parts of Malaysia, representing the Eastern Zone, the Central/South Zone, the Northern Zone, Sabah and Sarawak. Analysis of the data collected showed that the factors that facilitated success could be classified according to seven dimensions, namely (i) Attitude/Interest/Self-awareness, (ii) Capital, Good marketing, (iii) Innovative and Creative Thinking, (iv) Business Environment, (v) Experience and Knowledge, and (vi) Organization Management and External Cooperation. The results of the study showed that "Attitude/Interest/Self-awareness" was the factor that contributed most to the success of young entrepreneurs in the SMI sector. It can be concluded that a highly disciplined young person who is prepared to take risks, who is creative and innovative in his/her thinking and who is willing to improve his/her business know-how would be a good candidate to succeed as an SMI entrepreneur in Malaysia. SMI businesses could be expanded even globally, thereby contributing to the national economy. As part of the national plan to uplift the economy as a whole, while taking into account the factors that drive entrepreneurial success, the authorities should take steps to help and encourage young entrepreneurs who are willing to take up the challenge of venturing into the SMI sector.

Keywords: success factor, small and medium industry, entrepreneurship, challenges of the young entrepreneur, economic development

\section{Pengenalan}

Aktiviti keusahawanan dan perniagaan seperti IKS yang dijalankan akan membolehkan kita menentukan dan mengetahui tahap-tahap kemajuan yang telah dicapai oleh sesebuah masyarakat dan negara (Ab. Aziz, 2003). Golongan usahawan muda merupakan golongan yang dikenal pasti sebagai agen perubahan ekonomi dunia yang dapat dilihat pada masa kini melalui kejayaan mereka dalam bidang keusahawanan dan perniagaan (Lambing \& Kuehl, 2010). Mereka telah membuktikan kenyataan yang terlebih dahulu diperakui oleh Zenkin (1981) bahawa tanpa golongan usahawan muda aktiviti pembangunan sosioekonomi di sesebuah negara mungkin tidak akan berlaku. Oleh hal yang demikian, usahawan muda amatlah diperlukan oleh seluruh dunia kerana ia sering dikaitkan dengan kemajuan dan kerancakan pembangunan ekonomi negara. Kerajaan Malaysia sangat menitikberatkan untuk membangun dan melahirkan lebih ramai usahawan muda yang berjaya dalam bidang perniagaan IKS bagi membantu pembangunan ekonomi luar bandar selain memberikan bantuan kepada mereka untuk mengubah nasib hidup mereka dengan mencipta peluang pekerjaan baru. Hal ini kerana, golongan usahawan muda terdiri daripada mereka yang berumur dalam lingkungan 15-40 tahun dan masih lagi mempunyai kudrat dan bertenaga dalam menjalankan aktiviti keusahawanan dan perniagaan IKS (Norashidah, 2009).

Potensi belia dalam bidang keusahawanan dan perniagaan IKS perlu digilap di peringkat awal lagi dan perlulah ditambah baik dan berterusan demi mencapai kejayaan di dalam bidang tersebut. Di Malaysia secara keseluruhannya, golongan belia pada hari ini telah didedahkan kepada ilmu serta memiliki pelbagai bidang kemahiran dan pengetahuan tentang keusahawanan. Pengetahuan yang dimiliki oleh anak muda dan belia masa kini akan membentuk mereka menjadi seorang usahawan muda yang berjaya sekali gus membantu negara dalam aspek pembangunan sosioekonomi negara. Di Malaysia pihak kerajaan dan swasta memainkan peranan yang penting dalam menarik minat anak muda dan belia khususnya untuk menceburi bidang Industri Kecil dan Sederhana (IKS) khususnya di kalangan luar 
bandar. Sektor IKS ini dianggap penting memandangkan ia memberikan sumbangan yang besar kepada pendapatan negara yang dapat melahirkan usahawan berjaya. Usahawan yang berjaya bukan sahaja mencipta perniagaan baru malahan meningkatkan peluang pekerjaan yang menjurus kepada sumber penciptaan penemuan terbaru, teknologi baru dan inovasi.

Dalam usaha untuk membangunkan sektor Industri Kecil dan Sederhana (IKS) di Malaysia dan aktiviti keusahawanan di luar bandar sekali gus melahirkan usahawan muda, pihak kerajaan Malaysia telah memberi sepenuh tumpuan dengan melibatkan pelbagai kementerian dan institusi seperti Kementerian Pembangunan Usahawan, Kementerian Pembangunan Luar Bandar dan Wilayah, dengan kerjasama institusi dan agen-agen yang bertanggungjawab dan berkepentingan seperti Amanah Ikhtiar Malaysia (AIM), Tabung Ekonomi Usaha Niaga (TEKUN), Majlis Amanah Rakyat (MARA), Perbadanan Nasional Berhad (PNS), Bank Rakyat, Jabatan Pembangunan Koperasi (JPK), Maktab Kerjasama Malaysia (MKM) dan Syarikat Pembangunan Ekonomi Negeri (SEDCs) (Nor Azira et al., 2016 ). Tambahan lagi, kerajaan banyak membantu usahawan muda dari segi bantuan kewangan dan hal ini sedikit sebanyak mendorong kepada pertumbuhan IKS itu sendiri, kerana usahawan muda memerlukan sejumlah modal yang agak besar untuk melakukan sesuatu perniagaan (Zafir \& Fazirah, 2007).

Kejayaan usahawan muda dalam bidang IKS memberikan implikasi yang tinggi kepada masyarakat mahupun negara, hal ini dibuktikan melalui dapatan data KDNK yang saban tahun meningkat ekoran pertumbuhan IKS di negara ini. Perkembangan tersebut meningkat pada kadar purata tahunan $6.8 \%$ berbanding 4.9\% bagi keseluruhan ekonomi dalam tempoh 2004-2010 (Majlis Pembangunan IKS Kebangsaan, 2012). Oleh itu, kerajaan berharap usahawan muda akan terus berjaya dalam perniagaan IKS yang mana akan menjadi penyumbang penting dalam pertumbuhan sosioekonomi negara. Kajian ini cuba meneliti faktor kejayaan usahawan muda dalam perniagaan Industri Kecil dan Sederhana (IKS) di Malaysia agar dapat dijadikan panduan buat golongan naka muda dan belia yang lain untuk menceburi bidang perniagaan IKS dan berusaha untuk mencapai kejayaan dalam perniagaan yang dijalankan. Hal demikian, tidak dapat dinafikan, ramai golongan usahawan muda dan belia di negara ini yang telah menyumbang dalam pembangunan ekonomi negara. Oleh itu, kemajuan perniagaan di kalangan usahawan muda di Malaysia perlu dititikberatkan kerana mereka merupakan aset negara bagi pertumbuhan ekonomi negara.

\section{Kajian Literatur}

\section{Faktor Kejayaan Usahawan Muda dalam Perniagaan (IKS) di Malaysia}

Kerjaya dalam bidang keusahawanan dan perniagaan Industri Kecil dan Sederhana (IKS) semakin meningkat dan menjadi antara salah satu faktor utama yang menyumbang kepada pertumbuhan dan pembangunan ekonomi negara. Sektor ini telah menjadi pilihan kerjaya dalam kalangan generasi muda dan belia terutama di negara-negara progresif (Norasmah \& Sumathy, 2012). Begitu juga di Malaysia, jika dahulunya generasi muda kurang berminat untuk melibatkan diri dalam kerjaya keusahawanan di mana belia dalam umur 15-24 tahun juga rendah berdasarkan statistik Jabatan Perangkaan Malaysia 2009, Akan tetapi kini semakin bertambah dari semasa ke semasa disebabkan kesedaran diri generasi muda dan belia mengenai keuntungan dan kelebihan bidang keusahawanan dan perniagaan (IKS) yang mampu mengubah nasib hidup mereka. Hal ini kerana, menurut Kementerian Perdagangan Antarabangsa dan Industri Malaysia (2012) dorongan untuk menjadi usahawan muda berlaku disebabkan isu kesukaran untuk mendapatkan pekerjaan. Malaysia, merupakan sebuah negara yang sedang membangun memerlukan lebih ramai usahawan muda yang berjaya bagi membentuk masyarakat yang berpendapatan tinggi ke arah negara maju menjelang 2020. Oleh itu, generasi muda dan belia perlu bijak dalam merebut setiap peluang yang ada terutamanya dalam bidang perniagaan IKS dengan menjadi usahawan muda yang berjaya dan dapat membangun dengan peredaran semasa (Eriniwati, 2014).

Kajian lepas turut membuktikan bahawa kejayaan usahawan dapat dikenal pasti apabila usahawan memiliki ciri-ciri peribadi yang membezakan dengan individu yang lain dengan kesediaan untuk mencapai kejayaan dalam keusahawanan kerana mereka dapat melihat dan menganalisis persekitaran 
mereka dengan cekap sehingga mereka dapat menyalurkan potensi kreatif dan produktif yang tinggi serta menggunakan keupayaannya untuk mencapai pencapaian yang dingini. Definisi ini menunjukkan bahawa kejayaan keusahawanan belia dalam perniagaan bergantung kepada keupayaan diri mereka untuk meneroka pelbagai peluang persekitaran, menggunakan keupayaannya berdasarkan sumber yang ada dan keperluan untuk pencapaian diri iaitu motivasi dan kesedaran diri. Selain itu, menurut Carsrud dan Brannback (2009) menekankan bahawa kejayaan keusahawanan bergantung kepada pemikiran (kecenderungan) belia terhadap aktiviti keusahawanan. Kajian ini berpendapat bahawa potensi bakal menjadi usahawan muda berjaya adalah lebih cenderung kepada motivasi diri sendiri dan mempunyai pemikiran positif terhadap aktiviti keusahawanan. Sumber atau modal boleh didefinisikan sebagai "aset kewangan, fizikal, manusia, dan organisasi yang digunakan oleh firma untuk membangun, mengilang, dan menyampaikan produk atau perkhidmatan kepada pelanggannya demi mencapai kejayaan dalam perniagaan" (Barney, 1995).

Selain itu, menurut Mosakowski (1998) menyatakan bahawa sumber keusahawanan di sisi ditakrifkan sebagai "kecenderungan seseorang untuk mencari peluang-peluang baru bagi mendapatkan dana, berperilaku secara kreatif, bertindak dengan pandangan jauh dan menggunakan gerak hati dalam memperoleh modal perniagaan. Manakala, kajian lepas yang lain membahaskan mengenai faktor kejayaan usahawan menerusi faktor persekitaran seperti institusi keluarga dan kerajaan yang membantu dalam melancarkan segala gerak kerja perniagaan Ini bertepatan dengan kenyataan Martinelli (1994) yang berpendapat bahawa aspek persekitaran perniagaan sama ada sosial dan budaya turut memberikan sokongan dan menggalakkan kepada pembentukan kejayaan keusahawanan dalam perniagaan. Di samping itu, dalam usaha untuk mencapai kejayaan usahawan muda dalam perniagaan adalah faktor kemahiran ilmu pengetahuan, pemasaran yang baik dan juga pengurusan organisasi yang baik dan kerjasama jaringan luar. Menurut Audia dan Rider (2005) dalam kajian Ishak Yussof et al. (2001) mengatakan faktor pengetahuan dan kemahiran terhadap usahawan muda mengenai peluang dan potensi yang dimiliki oleh sesuatu industri. Ini bagi membolehkan usahawan berpandangan jauh berdasarkan pengetahuan perniagaan yang dimiliki serta kemahiran dalam membuat perancangan dan strategi bagi mencapai kejayaan perniagaan. Selain itu, hujah lain menyatakan bahawa faktor hubungan kerjasama dan jaringan luar adalah suatu hal yang penting dalam kejayaan keusahawanan kerana ianya dapat meluaskan pemasaran produk yang ditawarkan (Bron \& Markman, 2000).

\section{Kerangka Konseptual Kejayaan Usahawan Muda dalam Perniagaan IKS di Malaysia}

Kejayaan usahawan muda dalam perniagaan dapat dilihat menerusi Teori Gibbs dan Ritchie (1982) yang telah diubahsuai untuk membangunkan faktor atau komponen permulaan utama dalam kejayaan sesebuah perniagaan. Teori ini melihat kepada keusahawanan itu sebagai proses sosial. Ini kerana idea dan cita-cita muncul dalam keadaan sosial. Teori ini berpendapat bahawa seseorang usahawan muda dan belia itu boleh dibantu dan dibentuk dalam perniagaannya sehingga berjaya dan mampan. Walaupun personaliti individu merupakan perkara paling penting untuk berjaya, namun kejayaan seseorang usahawan muda mungkin dipengaruhi kerana pengaruh keluarga, pendidikan, pengalaman, sokongan dan dorongan dan sebagainya. Oleh itu, teori ini menunjukkan bahawa faktor persekitaran boleh mempengaruhi kehidupan individu ke arah mewujudkan perniagaan yang berjaya tanpa faktor genetik terhadap permulaan perniagaan yang baru.

Peringkat-peringkat yang perlu dilalui oleh seorang usahawan muda untuk mencapai perniagaan yang berjaya adalah bermula dari menemukan motif atau matlamat tentang mengapa sesuatu perniagaan itu harus dijalankan. Pada peringkat ini, seorang usahawan muda memerlukan kepada motivasi diri yang tinggi dalam perniagaan. Kemudian, selepas memperoleh matlamat tersebut, langkah seterusnya adalah untuk mengetahui idea kreatif dan inovatif yang berdaya maju. Idea ini mesti menarik dan disahkan sama ada ia dapat memenuhi keperluan dan permintaan pelanggan. Langkah seterusnya ialah mencari sumber yang diperlukan seperti bahan, sumber modal dan pendanaan serta pembekal barangan yang berkualiti bagi menghasilkan produk yang disukai orang ramai. Kemudian, teknik pemasaran yang baik bagi mempromosikan produk perniagaan di peringkat yang lebih meluas. Seterusnya adalah dengan meningkatkan kemahiran dan pengetahuan diri sendiri dalam bidang perniagaan. Selain itu, pengurusan organisasi dan kerjasama jaringan luar serta faktor persekitaran perniagaan yang sedikit sebanyak mempengaruhi perniagaan usahawan muda. Model asal ini dibahagikan kepada empat komponen 
kejayaan asas. Faktor-faktor ini adalah idea dan pasaran, motivasi dan keazaman, sumber dan keupayaan. Akan tetapi, pengkaji telah mengubahsuai teori konseptual mengikut kesesuaian perniagaan Industri Kecil dan Sederhana (IKS) di Malaysia.

Rajah1: Kerangka Konseptual Kejayaan Usahawan Muda dalam Perniagaan IKS di Malaysia

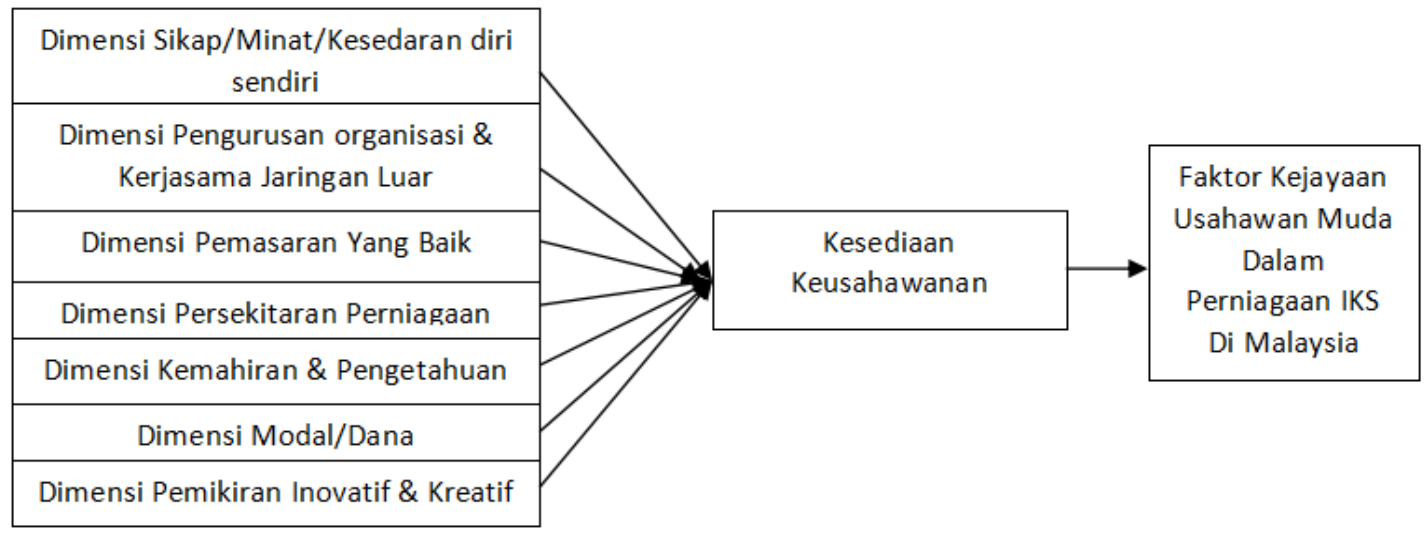

Sumber: Gibbs dan Ritchie (1982)

\section{Metod Kajian}

Kajian ini menggunakan pendekatan kaedah kuantitatif sepenuhnya yang menggunakan instrumen borang soal selidik untuk menganalisis faktor-faktor kejayaan usahawan muda dalam menghadapi cabaran perniagaan (IKS) di Malaysia. Borang soal selidik tersebut telah diubahsuai dan dipermudahkan ke dalam bentuk Google Forms bagi diedarkan dan dijawab oleh kesemua responden melalui e-mel responden. Hal ini kerana, kawasan kajian adalah melibatkan sekitar Malaysia iaitu Zon Utara, Zon Timur, Zon Tengah/Selatan, Zon Sabah dan juga Zon Sarawak yang terdiri daripada responden seramai 138 orang. Kesemua responden terdiri daripada para usahawan muda yang telah terlibat secara langsung di dalam Program Rural Business Challenges dan telah berjaya dalam perniagaan (IKS) masing-masing. Setiap responden diedarkan dengan borang soal selidik melalui Google Forms yang telah dihantar bagi mendapatkan maklumat yang diperlukan. Hasil soal selidik yang dijawab oleh responden dianalisis menggunakan frekuensi analisis deskriptif dengan menggunakan perisian SPSS.

\section{Dapatan Kajian dan Perbincangan}

Keterlibatan dan kejayaan usahawan muda dan belia dalam sektor industri kecil dan sederhana sangat penting dalam menjamin kelangsungan pembangunan sosioekonomi luar bandar. Oleh itu, pelbagai daya usaha yang efektif dan berterusan perlu dijalankan dari aspek dalaman mahupun luaran bagi membantu para usahawan muda ini untuk terus maju dan berjaya dalam perniagaan mereka, sektor (IKS) seterusnya meningkatkan kemajuan pembangunan luar bandar. Hasil penemuan kajian mendapati dimensi 'Sikap/Minat/Kesedaran diri sendiri' mencatat purata skor min tertinggi iaitu 4.35 yang menjadi pendorong utama buat usahawan muda untuk berjaya dalam perniagaan (IKS) di Malaysia. Kejayaan seseorang usahawan muda dalam bidang perniagaan (IKS) sangat penting dan berkait menerusi kesedaran diri mereka sendiri untuk berjaya dalam perniagaan yang mereka ceburi. Dimensi 'Sikap/Minat/Kesedaran diri sendiri' adalah merangkumi item 'Berdisiplin tinggi dalam mengurus dan mengendalikan perniagaan' (4.36), 'Bijak dalam mencari setiap peluang yang ada untuk mencapai kejayaan perniagaan' (4.36), 'Mempunyai matlamat yang jelas dan berusaha dalam meningkatkan kejayaan perniagaan' (4.39)' 'Meningkatkan ilmu pengetahuan dalam keusahawanan dan perniagaan' (4.33), 'Berani menanggung risiko yang bakal dihadapi dan berfikiran positif' (4.31)' 
'Kehendak dan kemahuan diri sendiri' (4.32), dan 'Motivasi diri tentang perusahaan yang dijalankan' (4.38).

Seseorang usahawan muda yang ingin berjaya perlulah mempunyai motivasi diri yang tinggi dalam perusahaan yang dijalankan. Keberanian untuk mengambil risiko dalam apa jua keadaan diperlukan dalam diri seorang usahawan bagi meningkatkan potensi diri sendiri sebagai seorang pengusaha dan perkembangan perniagaan yang dijalankan (Zafir \& Fazilah, 2007). Selain itu, menurut Abu Bakar et al. (2014) mengatakan bahawa seseorang usahawan perlulah mempunyai matlamat, tujuan atau visi yang jelas sebagai faktor penggerak dalam menjalankan sesebuah perniagaan. Golongan muda dan belia perlu menceburkan diri mereka dalam dunia perniagaan dengan berusaha mencari setiap peluang yang ada walau sekecil-kecil perniagaan sekalipun dan komited dalam usaha untuk memajukan perniagaan yang diusahakan. Mempersiapkan diri dengan ilmu pengetahuan dalam keusahawanan dan perniagaan sangatlah penting sepanjang proses perniagaan demi meningkatkan tahap kemajuan perniagaan (Ab. Aziz Yusof, 2003). Di samping itu, dalam menjalankan perniagaan seorang usahawan perlu sentiasa berdisiplin dan memberikan komitmen yang tinggi dalam setiap kerja yang dilakukan bagi mencapai perkembangan perusahaan yang dijalankan (Ishak Yussof et al, 2011).

Bagi meningkatkan tahap keupayaan diri mereka dalam sektor IKS, para usahawan muda seharusnya menghadiri pelbagai kursus yang telah dianjurkan oleh pihak kerajaan mahupun swasta seperti Kementerian Pembangunan Usahawan, Kementerian Pembangunan Luar Bandar dan Wilayah dengan kerjasama institusi Majlis Amanah Rakyat (MARA), Jabatan Pembangunan Koperasi (JPK) dan sebagainya dalam usaha untuk memajukan diri usahawan muda itu sendiri di samping meningkatkan kemajuan pembangunan luar bandar di Malaysia menerusi kejayaan para usahawan muda dalam perniagaan IKS. Menurut Azmi, Nik dan Yee (2012) mengatakan bahawa kehendak dan kemahuan dalam diri seseorang usahawan menjadi antara faktor yang akan mempengaruhi mereka untuk terus maju dan berjaya dalam perniagaan yang diusahakan selain berusaha untuk merangka perancangan dan strategi bagi kejayaan perniagaannya (Lussier \& Halabi, 2010). Maka, seseorang usahawan muda yag ingin berjaya perlu memiliki nilai motivasi dalam diri mengenai perusahaan yang dijalankan berpandukan matlamat dan visinya yang jelas (Nor Azira et al., 2016).

Dimensi 'Modal/Dana' menunjukkan purata skor min kedua tertinggi (4.34) bagi faktor kejayaan usahawan muda dalam perniagaan (IKS) di Malaysia. Hasil keputusan analisis mendapati item 'Mendapatkan bantuan kewangan daripada pihak swasta/kerajaan' (4.38), 'Mempunyai rakan kongsi perniagaan yang boleh dipercayai dan bergantung harap' (4.28) dan 'Bantuan kewangan daripada hasil inisiatif usahawan sendiri' (4.36). Keperluan dalam memperoleh modal dan dana buat usahawan dalam amatlah penting demi kelangsungan perniagaannya serta kemajuan sektor IKS di luar bandar. Pelbagai kemudahan bantuan kewangan yang disediakan oleh institusi kerajaan dan swasta dalam usaha membantu para usahawan untuk berjaya dalam perniagaan. Bantuan kewangan ini akan disalurkan menerusi agensi-agensi yang berkepentingan dan bertanggungjawab untuk membantu para usahawan di Malaysia. Tambahan lagi, terdapat juga penawaran geran dan insentif penyelidikan buat usahawan dan pengusaha IKS untuk menjalankan aktiviti keusahawanan seperti Perbadanan Industri Kecil \& Sederhana (SMIDEC), Kementerian Pertanian dan Industri Asas Tani (MOA), Lembaga Kemajuan Perindustrian Malaysia (MIDA) dan pelbagai lagi yang memberikan platform buat para pengusaha untuk mendapatkan bantuan kewangan dalam menjalankan perusahaan yang dijalankan.

Selain itu, sebagai seorang usahawan yang berjaya seharusnya bijak untuk mencari inisiatif sendiri bagi mendapatkan modal dan dana kewangan perniagaan sebagai contoh dengan mempelbagaikan aktiviti ekonomi serta terlibat secara langsung dalam program yang menawarkan bantuan kewangan dan keperluan kepada para usahawan muda khususnya. Sebagai contoh, program Inisiatif Melestari Pembangunan Komuniti (1MPAK) yang membantu dari aspek kewangan, bimbingan dan latihan buat golongan anak muda dan belia untuk menjadi usahawan muda yang berjaya. Menurut Timbalan Pengarah Keusahawanan MARA mengatakan bahawa ini merupakan satu platform buat anak muda dan belia yang berminat untuk menjalankan aktiviti keusahawanan dan bercita-cita menjadi usahawan muda yang berjaya di samping fokus utamanya bagi mencapai mobiliti sosial dan ekonomi komuniti setempat yang baik selaras dengan matlamat Kementerian Kemajuan Luar Bandar dan Wilayah. Di samping itu, mempunyai rakan kongsi perniagaan yang boleh dipercayai juga turut membantu seorang 
pengusaha untuk berjaya dalam mendapatkan modal perniagaannya selain membantu dalam mengurus dan mentadbir hal ehwal berkaitan perniagaan seperti aspek kewangan, pengurusan, membuat keputusan, penstafan dan sebagainya (Mathew, 2003).

Seterusnya, faktor yang mendorong usahawan muda untuk berjaya dalam perniagaan adalah dimensi 'Pemasaran yang baik' yang menunjukkan purata skor min ketiga tertinggi iaitu (4.31). Item dalam pemasaran yang baik merangkumi 'Sentiasa mengemas kini senarai produk dan pelanggan/pengguna lama dan baru untuk tujuan pasaran produk akan datang, (4.28), 'Membuat promosi pasaran dengan efisien dan berterusan, (4.31), 'Mempunyai kemahiran sosial yang baik untuk mendekati pelanggan' (4.33), 'Mempunyai pengetahuan yang baik mengenai produk yang dipasarkan' (4.34), Memberikan potongan harga kepada pelanggan tetap dan pembelian secara pukal, (4.31) dan 'Mengembangkan pasaran produk dengan lebih luas' (4.28). pemasaran merupakan sebuah langkah bagi memperkenalkan servis atau produk yang dipasarkan kepada orang ramai dan difokuskan kepada prospek yang berminat tidak hanya sekadar teknik penawaran produk yang hebat malahan pengusaha perlu mengambil kira untuk menyasarkan iklan kepada prospek yang tepat (Sean \& Morgan, 2017). Mengembangkan pasaran produk dengan lebih luas sehingga ke peringkat yang lebih tinggi seperti di peringkat global semestinya menjadi satu impian dan pengharapan dalam diri setiap usahawan. Hal ini kerana, apabila seorang pengusaha mempunyai teknik pemasaran yang baik, maka produk yang dipasarkan dapat dipromosikan dengan lebih komersial dan ini sangat penting bagi menjana pendapatan perniagaan. Selain itu, mempunyai pemasaran yang baik membolehkan prospek mengenal produk anda dengan lebih mendalam. Bisnes yang baik adalah bisnes yang terus berkembang dan dikenali akan servis dan produk yang dikeluarkan. Dengan mempunyai kemahiran sosial yang baik, seorang usahawan dapat mendekati sasaran pelanggan dengan lebih efektif dan berkesan menerusi bujukan, promosi, pengetahuan produk yang baik dan lain-lain serta pemotongan harga bagi mereka yang menjadi pelanggan tetap produk yang dipasarkan agar mereka terus kekal setia membeli produk yang dikeluarkan.

Dimensi 'Pemikiran kreatif dan inovatif' juga penting buat usahawan muda dan belia untuk berjaya dalam bidang perniagaan (IKS) di Malaysia. Item bagi dimensi ini adalah 'Berinovasi dalam menambah baik kualiti produk perniagaan' (4.31), 'Kreatif dalam memasarkan dan mempromosikan produk perniagaan' (4.25) dan juga 'Pengeluaran produk perniagaan mempunyai ciri keistimewaan tersendiri dan serba guna' (4.28). Kreativiti dan inovasi adalah intipati keusahawanan. Keusahawanan pula memainkan peranan yang penting dalam pertumbuhan ekonomi sesebuah negara. Seseorang yang ingin menjadi usahawan akan menjadikan kreativiti dan inovasi sebagai perkara yang selalu diutamakan dalam semua aspek perniagaannya. Bagi perniagaan kecil dan sederhana, kreativiti dan inovasi adalah penting bagi mengekalkan kelebihan kemampuan berdaya saing masing-masing. Melalui kreativiti, usahawan boleh menghasilkan produk yang mempunyai kelainan daripada produk yang dikeluarkan oleh pesaing. Justeru, produk yang dihasilkan itu akan terus kekal di pasaran dan terus diminati oleh pelanggan hasil daripada perubahan terhadap beberapa ciri produk (Mohani, Kamaruzaman, Zainal \& Abdul Jumaat, 2008). Menurut Schermerhorn, Hunt dan Osborn (2003). Selain itu, menurut De Bono et al. (1970) menyatakan bahawa kreativiti melibatkan perkembangan inovasi produk yang tiada tolok bandingnya dan merupakan jawapan kepada masalah dan peluang yang diperoleh buat usahawan untuk menghasilkan sesuatu produk yang mampu menarik perhatian orang ramai. Justeru, kreativiti amat mustahak untuk bertindak balas kepada masalah yang kompleks dalam persekitaran perniagaan yang selalunya penuh dengan permasalahan yang tidak tetap. Seorang usahawan juga seharusnya kreatif dalam memasarkan produknya menerusi kemajuan perkembangan teknologi masa kini. Menurut Ismail (2004) kreativiti adalah ciri-ciri yang menunjukkan kebolehan seseorang menghasilkan kerja yang "asli". Ini menunjukkan tidak ada unsur-unsur peniruan dalam sesuatu penghasilan tetapi lahir dari pemikiran dan usaha usahawan itu sendiri.

Jadual 1: Faktor Kejayaan Usahawan Muda dalam Perniagaan (IKS) di Malaysia

\begin{tabular}{llll}
\hline Bil & Item & Skor & Tahap \\
& & Min & Kepentingan \\
\hline 1. & Dimensi Modal / Dana & $* 4.34$ & Tinggi \\
\hline
\end{tabular}


DOI: https://doi.org/10.47405/mjssh.v5i12.614
i. Mendapatkan bantuan kewangan daripada pihak swasta/kerajaan
ii. Mempunyai rakan kongsi perniagaan yang boleh dipercayai dan bergantung harap
iii. Bantuan kewangan daripada hasil inisiatif usahawan sendiri
2. Dimensi Pemasaran Yang Baik
i. Sentiasa mengemaskini senarai produk dan pelanggan/pengguna lama dan baru untuk tujuan pasaran produk akan datang
ii. Membuat promosi pasaran dengan efisien dan berterusan
iii. Mempunyai kemahiran sosial yang baik untuk mendekati pelanggan
iv. Mempunyai pengetahuan yang baik mengenai produk yang dipasarkan
v. Memberikan potongan harga kepada pelanggan tetap dan pembelian secara pukal
vi. Mengembangkan pasaran produk dengan lebih luas

\section{Dimensi Kemahiran dan Pengetahuan}

i. Mempunyai ilmu pengetahuan yang baik dan luas mengenai bidang perniagaan yang diceburi

ii. Mempunyai matlamat dan perancangan yang teliti dalam perniagaan

iii. Idea yang dikeluarkan saya mempengaruhi kepada pencapaian perniagaan saya.

iv. Mempunyai modul operasi bisnes sendiri

v. Bersikap professional dan mampu membuat keputusan dengan baik apabila menghadapi masalah

\section{Dimensi Persekitaran Perniagaan}

i. Institusi kekeluargaan, kerajaan, pendidikan menjadi antara tulang belakang dalam memberikan sokongan dan dorongan motivasi kepada usahawan untuk terus berjaya

ii. Pemilihan lokasi perniagaan yang strategik dan bersesuaian dengan bidang perniagaan yang dijalankan membantu usahawan untuk berjaya

iii. Politik dan ekonomi juga mempengaruhi prestasi sesebuah perniagaan dan kejayaan usahawan

\section{Dimensi Sikap/Minat/Kesedaran Diri Sendiri}

i. Berdisiplin tinggi dalam mengurus dan mengendalikan perniagaan

ii. Bijak dalam mencari setiap peluang yang ada untuk mencapai kejayaan perniagaan

iii. Mempunyai matlamat yang jelas dan berusaha dalam meningkatkan kejayaan perniagaan
*4.31 Tinggi

4.28 Tinggi

4.31 Tinggi

4.33 Tinggi

4.34 Tinggi

4.31 Tinggi

4.28 Tinggi

*4.21 Tinggi

4.33 Tinggi

4.32 Tinggi

4.22 Tinggi

4.12 Tinggi

4.07 Tinggi

*4.19 Tinggi

4.32 Tinggi

4.02 Tinggi

4.23 Tinggi

*4.35 Tinggi

4.36 Tinggi

4.36 Tinggi

4.39 Tinggi

iv. Meningkatkan ilmu pengetahuan dalam keusahawanan 4.33 Tinggi 


\begin{tabular}{|c|c|c|c|c|}
\hline & & dan perniagaan & & \\
\hline & $\mathrm{v}$. & $\begin{array}{l}\text { Berani menanggung risiko yang bakal dihadapi dan } \\
\text { berfikiran positif }\end{array}$ & 4.31 & Tinggi \\
\hline & vi. & Kehendak dan kemahuan diri sendiri & 4.32 & Tinggi \\
\hline & vii. & Motivasi diri tentang perusahaan yang dihasilkan & 4.38 & Tinggi \\
\hline \multirow[t]{7}{*}{6.} & \multicolumn{2}{|c|}{ Dimensi Pengurusan Organisasi \& Kerjasama Jaringan Luar } & $* 4.27$ & Tinggi \\
\hline & i. $\quad \mathrm{l}$ & Mempunyai sistem kewangan yang sistematik dan baik & 4.33 & Tinggi \\
\hline & i. & $\begin{array}{l}\text { Sistem pengurusan pekerja mengikut kemahiran dan } \\
\text { kepakaran }\end{array}$ & 4.26 & Tinggi \\
\hline & ii. & Mempunyai urus tadbir yang cekap dan baik & 4.29 & Tinggi \\
\hline & iii. & Kerjasama dengan agensi pemasaran & 4.32 & Tinggi \\
\hline & iv. & Kerjasama dengan agensi penyelidikan & 4.12 & Tinggi \\
\hline & $\mathrm{v}$. & Kerjasama dalam karnival anjuran FAMA \& MAEPS & 4.31 & Tinggi \\
\hline \multirow[t]{4}{*}{7.} & \multicolumn{2}{|c|}{ Dimensi Pemikiran Kreatif Dan Inovatif } & $* 4.28$ & Tinggi \\
\hline & i. & $\begin{array}{l}\text { Berinovasi dalam menambah baik kualiti produk } \\
\text { perniagaan }\end{array}$ & 4.31 & Tinggi \\
\hline & ii. & $\begin{array}{l}\text { Kreatif dalam memasarkan dan mempromosikan produk } \\
\text { perniagaan }\end{array}$ & 4.25 & Tinggi \\
\hline & iii. & $\begin{array}{l}\text { Pengeluaran produk perniagaan yang mempunyai ciri-ciri } \\
\text { keistimewaan tersendiri dan serba guna }\end{array}$ & 4.28 & Tinggi \\
\hline
\end{tabular}

Nota: * =Purata Skor Min

Hasil penemuan kajian menunjukkan bahawa faktor dimensi 'Pengurusan organisasi \& kerjasama luar' mencatatkan purata skor min (4.27). Item yang terlibat dalam dimensi ini adalah 'Mempunyai sistem kewangan yang sistematik dan baik' (4.33), 'Sistem pengurusan pekerja mengikut kemahiran dan kepakaran' (4.26), 'Mempunyai urus tadbir yang cekap dan baik' (4.29), 'Kerjasama dengan agensi pemasaran' (4.32), 'Kerjasama dengan agensi penyelidikan' (4.12), 'Kerjasama dalam karnival anjuran FAMA \& MAEPS' (4.31). Perniagaan yang berjaya memerlukan kepada sistem pengurusan organisasi yang sistematik dan baik dalam aspek kewangan terutamanya bagi mencapai matlamat utama perniagaan di samping menjaga kestabilan perniagaan. Di samping itu, pembahagian pekerja mengikut kemahiran dan kepakaran masing-masing amat penting bagi memastikan kelancaran perjalanan keseluruhan sesebuah organisasi perniagaan serta meningkatkan proses pengeluaran produk yang dipasarkan (Rom \& Rohde, 2006). Selain itu, usahawan yang berjaya memerlukan kepada pengurusan perniagaan yang baik untuk memastikan semua faktor pengeluaran dalam perniagaan digunakan secara berkesan dan dapat diselaraskan dan diagihkan secara baik dan teratur serta tiada pembaziran sumber yang dilakukan. Kerjasama luar juga memainkan peranan yang penting buat usahawan muda untuk menambahbaikkan kualiti serta pasaran produk. Sebagai contoh, kerjasama penyelidikan menerusi Skim geran penyelidikan dan pembangunan Koridor Raya Multimedia yang bertujuan untuk membantu penyelidikan para usahawan selain menawarkan modal perniagaan. Kerjasama luar ini sangat membantu usahawan muda untuk mengkomersialkan produk mereka di peringkat tempatan mahupun global sekali gus membantu akses produk IKS tempatan dikenali di pasaran eksport utama.

Tambahan lagi, faktor yang dikenal pasti bagi mencapai kejayaan usahawan muda dalam perniagaan (IKS) adalah dimensi 'Kemahiran dan pengetahuan' yang mencatat purata skor min (4.21). Dimensi ini merangkumi item 'Mempunyai ilmu pengetahuan yang baik dan luas mengenai bidang perniagaan yang diceburi' (4.33), 'Mempunyai matlamat dan perancangan yang teliti dalam perniagaan, (4.32), 
'Idea yang dikeluarkan saya mempengaruhi kepada pencapaian perniagaan saya' (4.22), 'Mempunyai modul operasi bisnes sendiri' (4.12) dan juga 'Bersikap profesional dan mampu membuat keputusan dengan baik apabila menghadapi masalah' (4.07). Seorang usahawan perlu untuk mempunyai ilmu pengetahuan yang mendalam, baik dan luas mengenai bidang perniagaan yang diceburi agar dapat merangka strategi-strategi perkembangan perniagaan dengan lebih berkesan berdasarkan kepada prospek yang dikaji. Selain itu, dimensi ini juga bertepatan dengan definisi seorang usahawan itu sendiri iaitu seseorang individu yang mempunyai matlamat yang jelas dalam perusahaan yag dijalankan, mempunyai pengetahuan perniagaan, berani menanggung risiko, mampu membuat keputusan dengan baik dalam apa jua situasi permasalahan (Zafir \& Fazilah, 2007). Idea kreatif yang dikeluarkan menerusi pengetahuan yang dimiliki usahawan akan mempengaruhi kepada pencapaian perniagaannya dengan memiliki modul operasi bisnes yang tersendiri bagi digunakan sebagai rujukan dalam keseluruhan perjalanan perniagaan. Pelbagai program keusahawanan dalam kalangan anak muda dan belia luar bandar dapat dilaksanakan bagi meningkatkan tahap kemahiran dan pengetahuan para usahawan muda di samping membantu mereka dari sudut kewangan, latihan, bimbingan dan perlaksanaan. Sebagai contoh, program inisiatif yang dianjurkan oleh Kementerian Kemajuan Luar Bandar dan Wilayah iaitu Rural Business Challenges yang bertujuan untuk membantu mereka untuk keluar dari garis kemiskinan dan melahirkan usahawan muda yang berjaya di sekitar Malaysia sekali gus meningkatkan kemajuan pembangunan luar bandar.

Faktor yang terakhir adalah dimensi 'Persekitaran perniagaan' yang mencatat purata skor min (4.19). Faktor ini juga dilihat memainkan peranan yang penting dalam mencapai kejayaan dalam perniagaan (IKS) buat usahawan muda di Malaysia. Menerusi analisis kajian mendapati responden bersetuju bahawa 'Institusi kekeluargaan, kerajaan dan pendidikan menjadi antara tulang belakang dalam memberikan sokongan dan dorongan motivasi kepada usahawan untuk terus berjaya' (4.32), 'Pemilihan lokasi perniagaan yang strategik dan bersesuaian dengan bidang perniagaan yang dijalankan membantu usahawan untuk berjaya' (4.02) dan 'Politik dan ekonomi juga mempengaruhi prestasi sesebuah perniagaan dan kejayaan usahawan' (4.23). Dorongan dan sokongan daripada institusi berkepentingan seperti keluarga, kerajaan dan pendidikan merupakan antara elemen penting dalam kejayaan seseorang usahawan. Semangat dan dorongan mereka memberikan satu anjakan paradigma buat diri mereka untuk terus berusaha dan berjaya dalam bidang perniagaan yang diusahakan. Aspek bantuan kewangan, inisiatif program, latihan dan bimbingan sangat membantu usahawan muda untuk meningkatkan daya kemandiriannya dalam perniagaan. Manakala, politik dan ekonomi juga mampu mempengaruhi sesebuah perniagaan tersebut. Ketidakstabilan politik dan ekonomi akan mengakibatkan daya pengeluaran dan penjanaan pendapatan perniagaan berkurangan disebabkan inflasi (Prattern, 2004). Aspek lokasi yang strategi berdasarkan jenis perniagaan juga memainkan peranan penting dalam membantu memasarkan produk perniagaan. Ini kerana, ia mungkin menjadi titik tolak kunjungan pelanggan ke lokasi perniagaan disebabkan oleh kawasannya yang senang untuk dikunjungi dan menjadi tumpuan orang ramai. Kejayaan usahawan muda dalam perniagaan bergantung kepada beberapa faktor persekitaran lokasi seperti buruh sama ada dari segi kualiti atau kuantiti, pengangkutan dan perhubungan, tapak bangunan dan bantuan kerajaan sebelum membuat keputusan pemilihan lokasi (Glasson, 1978).

\section{Kesimpulan}

Segala faktor dimensi tersebut sangat diperlukan oleh seseorang usahawan untuk mencapai kejayaannya sekali gus bagi meningkatkan pembangunan ekonomi negara dan usaha ini harus berterusan dilaksanakan untuk menambahbaikkan kualiti kehidupan komuniti dan masyarakat setempat. Keberkesanan faktor kejayaan usahawan dalam perniagaan IKS di Malaysia boleh dibahagiakan kepada faktor dalaman dan luaran iaitu faktor dalaman yang berkait rapat dengan diri usahawan itu sendiri dan faktor luaran yang berkaitan dengan kerjasama institusi luar seperti kerajaan, swasta dan agensi-agensi yang bertanggungjawab dan berkepentingan. Hasil kajian keseluruhan mendapati semua faktor dimensi dan item adalah pada tahap kepentingan yang tinggi. Maka, pemerkasaan diri usahawan muda untuk berjaya dalam perniagaan IKS di Malaysia perlu didasarkan dengan tujuh faktor tersebut iaitu dimensi 'Sikap/minat/kesedaran diri sendiri', diikuti dimensi 'Modal/dana', dimensi 'Pemasaran yang baik', dimensi 'Pemikiran inovatif dan kreatif', dimensi 
'Pengurusan organisasi dan kerjasama jaringan luar', dimensi 'Kemahiran dan pengetahuan' dan dimensi 'Persekitaran perniagaan'. Oleh itu dalam mendepani segala cabaran untuk menjadi usahawan muda yang berjaya terdapat beberapa perkara yang perlu dikuasai antaranya ialah kemahiran penggunaan teknologi ICT, disiplin yang tinggi dalam perniagaan dan menjangkakan keperluan pada masa depan.

\section{Rujukan}

Ab. Aziz Yusof. (2003). Prinsip Keusahawanan. Prentice Hall. Pearson Malaysia Sdn. Bhd.

Aishah Kasa. (2009). Pembangunan Instrumen Pengukuran Psikologi Keusahawanan Belia Malaysia. Serdang. Universiti Putra Malaysia.

Bukryman Sabri et al. (2008). Kajian Aspirasi Keusahawanan Belia Terhadap Memupuk Budaya Keusahawanan Ke Arah Menuju Pencapaian Wawasan 2020. Kementerian Belia dan Sukan. Institusi Penyelidikan Pembangunan Belia Malaysia.

De Bono (1970). Parallel Thinking: From Socratic Thinking to de Bono Thinking. Penguin Books: United Kingdom.

Drucker, P. (1985). Innovation and Entrepreneurship. Amazon.com. United States.

Dunn, P. (2011). A Comparison of Entrepreneurship/Small Business and Finance Professor's Reaction To Selected Entrepreneurial and Small Business Financial Planning and Management Issue. Journal of Entrepreneurship Education.

Eriniwati Aliza. (2014). Faktor Yang Mendorong Kecenderungan Pelajar Kolej Vokasional Ke Arah Bidang Keusahawanan. Tidak Diterbitkan. Ijazah Sarjana Pendidikan Teknikel. Fakulti Pendidikan Teknikal dan Vokasional, Universiti Tun Hussein Onn Malaysia.

Gibb, A. A, J. Ritchie. (1982). Understanding the Process Of Starting Small Business. European Small Business Journal, 1(1).

Green, F. (2013). Youth Entrepreneurship, A Background Paper for the OECD Center for Entrepreneurship, SMEs and Local Development.

Greene. (2000). The Power of Entrepreneurial Vision Vocational Education, Educational Journal, 64(8), 28-29.

Hisrich, R. D. (2000). Marketing. Second Edition. United States of America: Barron's Education Series. Inc.

Ishak Yussod et al. (2011). Faktor Keusahawanan dan Prestasi Kejayaan Usahawan Melayu di Pulau Langkawi, Kedah. Persidangan Kebangsaan Ekonomi Malaysia ke VI (PERKEM VI) Pusat Pengajian Ekonomi, Fakulti Ekonomi dan Pengurusan, Universiti Kebangsaan Malaysia, 5-7 Jun 2011, Melaka Bandaraya Bersejarah.

Ismail Zain (2004) Apa itu Kreativiti? Portal Pendidikan Utusan. Utusan Melayu(M)Berhad. http://www.tutor.com.my/tutor/dunia.asp?y=2004\&dt=0527\&pub=DuniaPendidikan\&sec=Kauns eling\&pg=ka_01.htm. Dibaca 23.5.09

Jabatan Perangkaan Malaysia. (2009). Siaran Khas Penyiasatan Tenaga Buruh (Usahawan Di Malaysia), Siri 4 Bil 1. 1/2009. Malaysia. Jabatan Perangkaan Malaysia.

Kementerian Perdagangan Antarabangsa dan Industri Malaysia (2012). Laporan MITI. Kuala Lumpur. Sasyaz holdings Sdn. Bhd

Lambing, P. A. \& Kuehl, C. R. (2000). Entrepreneurship: Third Edition. New Jersey: Prentice Hall

Martinelli, A. (1994). Entrepreneurship and management in Smelster, N.J and Swedberg, R (Eds.) The Handbook of Economics Sociology. Princeton, NJ : Priceton University Press.

Mohd Nor Hidayad Hambali. (2011). Faktor Bantuan Kerajaan yang Meningkatkan Kejayaan Usahawan Industri Kecil dan Sederhana Bumiputera di Sabak Bernam, Selangor. Tidak Diterbitkan. Tesis Sarjana Muda, Fakulti Pendidikan, Universiti Teknologi Malaysia, Skudai.

Mohani Abdul, Kamaruzaman Ismail, Zainal Abidin Mohamed dan Abdul Jumaat Mahajar (2008). Pembudayaan Keusahawanan. Pearson Prentice Hall: Kuala Lumpur.

Norashidah Othman, Noraishah Buang. (2009). Konsep Kesedian Keusahawanan Berdasarkan Kajian Kes Usahawan IKS di Malaysia. Jurnal Pendidikan Malaysia, 34(1), 187-203.

Nor Azira Ayob, Sity Daud \& Muhamad Takiyuddin Ismail. (2016). Faktor pembentukan modal insan dan daya saing usahawan wanita Malaysia: Kajian empirikal wanita bumiputera di Melaka. GEOGRAFIA OnlineTM Malaysian Journal of Society and Space, 12(5), 115 - 129. 
Norasmah Othman \& Sumathy a/p Panniappan. (2012). Profil Keusahawanan Peniaga India India di Malaysia.

Schermerhorn, Hunt \& Osborn (2003) Organizational Behaviour. The Jossey-Bass: New York Zafir \& Fazirah. (2007). Menjadi Usahawan. PTS Bisnes dan Pengurusan. Kuala Lumpur.

Zenkin, M. (1981). Entrepreneurs. Key to Growth. Standford Research Institute Journal, 43-48. 